\title{
Investigating the prevalence of child abuse in the families with addicted parents in Iran: With emphasis on family risk factors
}

\author{
Vahid Farnia, Faeze Tatari, Mehdi Moradinazar, Safora Salemi**, Toraj Ahmadi Juibari, \\ Mostafa Alikhani, Nasrin Abdoli, Sanobar Golshani \\ Substance Abuse Prevention Research Center, Health Institute, Kermanshah University of Medical Sciences, Kermanshah, Iran
}

\section{A R T I C L E I N F O}

\section{Keywords:}

Child abuse

Addiction

Parents

\begin{abstract}
A B S T R A C T
Introduction: Violence against children has become rampant, especially among the families with addicted parents. Accordingly, the present research was conducted to investigate the prevalence of child abuse among the families with addicted parents in the west of Iran taking into account family risk factors.

Methodology: The present research was performed with a cross-sectional design. The statistical population included all the addicted parents having the 6-12-year-old children who referred to the Narcotic Treatment Centers in Kermanshah province, Iran during 2017-2018, among which 273 subjects were randomly selected to be included in the study and filled out the Child Abuse Potential (CAP) Inventory.

Results: The results showed that the prevalence of physical and psychological abuse was equal to $43.2 \%$. After controlling the influencing variables, child abuse among the boys was reported to be 0.67 times more than that of the girls. Furthermore, with the increase in the number of siblings, the chances of child abuse were escalated so that, those with three or more than three siblings were 2.92 times more likely to be abused than those without siblings. Being a homemaker mother increased the chance of child abuse by 0.62 times, and the occurrence of psychological problems in the family increased the chance of child abuse by 2.56 times. The chance of child abuse among the parents who were both addicted was 2.66 times more than the families where the father alone was addicted.

Conclusion: Given high prevalence of child abuse among the families with drug-addicted parents, supportive organizations are required to play a more prominent role, and it would be also essential to provide effective care programs for empowerment of the children.
\end{abstract}

Child abuse is observed in all the human societies with different ethnicities, races and social and cultural levels. ${ }^{1}$ According to The World Health Organization (WHO), child abuse is defined as a complex issue involving the physical and psychological abuse, sexual abuse, neglect, as well as commercial or other forms of exploitation. ${ }^{2}$ In most cases, child abuse should be considered an indication of a disorder in the whole family and appropriate approach can be taken to eliminate it only by understanding the factors involved in this problem. ${ }^{3}$ Drug addiction and its associated mood and behavioral changes are among the risk factors for child abuse. ${ }^{4}$ Parental addiction has a long lasting effect on the health and safety of the children, and drug and alcohol abuse usually contributes in development of all kinds of child abuse. ${ }^{4}$ According to the statistics published by the Welfare Organization, parental addiction is the main cause of referral for $57 \%$ of child abuse cases to this organization. Because addicted parents often suffer from low selfesteem, anxiety and depression, leading them to commit child abuse. ${ }^{5}$
Living with addicted parents has serious consequences for the children. ${ }^{4}$ In the families with addicted parents, financial, health, and emotional problems can cause tension in the family that can be manifested as child or spouse abuse. ${ }^{6}$ Usually, addicted parents are incapable of satisfying their children's physical needs and supporting them emotionally and their children suffer from various problems. ${ }^{7}$ Addiction makes the parents less likely to control their behaviors and impulses, having less preventive behaviors and resulting in more abusive behaviors against their children. ${ }^{8}$ Abusive behaviors against the children lead to persistent and unfavorable consequences for them including weakness in memory, ${ }^{9}$ immature communication, ${ }^{10}$ weakness in emotion regulation, ${ }^{11}$ cognitive problems, ${ }^{12}$ and anti-social behaviors. ${ }^{13}$ Also, child abuse experience increases the likelihood of long-term mental diseases in the adulthood such as severe depression, anxiety, drug and alcohol addiction. ${ }^{14}$

Child abuse and mistreatment with children and adolescents is a

\footnotetext{
* Corresponding author. Substance Abuse Prevention Research Center, Health Institute, Kermanshah University of Medical Sciences, Kermanshah, Iran.

E-mail address: s_salemi85@yahoo.com (S. Salemi).
} 
problem causing the pain in the present and future life of children. In addition, it imposes high costs on the treatment of the effects and complications caused by child abuse. ${ }^{15}$ Therefore, conducting the researches aimed at investigating the prevalence and dimensions of child abuse and identifying the risk factors of child abuse in the family can lead to better planning for helping these children. In this regard, it is necessary to understand the prevalence of child abuse, especially in the families with addicted parents. Therefore, the present study was conducted to determine the prevalence of child abuse in the families with drug-addicted parents and to investigate the family risk factors associated with this issue.

\section{Methodology}

\subsection{Subjects}

The present cross-sectional study was conducted in Kermanshah, Kermanshah province, Iran, from December 2017 to July 2018. The statistical population consisted of all the addicted parents who referred to the Narcotic Treatment Centers (to receive Methadone Maintenance Treatment (MMT)) affiliated to Kermanshah University of Medical Sciences, Kermanshah, Iran among which, 290 addicted parents were randomly selected to be included in the study. Although, 17 questionnaires were not returned or responded incompletely; for this reason, 273 questionnaires were analyzed. For selection of the addicted parents, six centers were visited and the purpose of the study was described by the researchers to the managers, staff, and psychologists then, the questionnaires were provided to the psychologists of these centers. The questionnaires were given to the subjects after eligibility assessment according to the inclusion and exclusion criteria. Inclusion criteria included addiction to opium by one parent or both of them, having at least one child aged 6-12 years old, willingness to participate in the research, positive history of drug addiction for at least one year, and having the lowest level of literacy. Exclusion criteria included alcohol and other substances abuse during the past 5 years, and a history of taking medicines and neurological diseases.

\subsection{Measures}

\subsubsection{Child Abuse Potential (CAP) questionnaire}

The CAP questionnaire has been used previously in the Iranian society to measure the child abuse. ${ }^{16}$ This questionnaire is a Likert-type scale consisting of three subscales including psychological abuse, physical abuse, and neglect, as well as a total score called an abuse scale. In Iran, Hossein Khani et al. have evaluated the validity of the inventory after reviewing the existing relevant literature and preparing the initial version by calculating the clarity and relevance, and also measured the reliability of the inventory through the Cronbach's alpha and estimated the repeatability using the Intraclass Correlation Coefficient (ICC) and two-week test-retest intervals. In their research, the mean clarity and relevance of the inventory was equal to 80.36 and 92.5 , respectively, and the range of relevancy of the items was between 90.14 and 97.2. The mean ICC and Cronbach's alpha was equal to 0.95 and 0.92 , respectively. ${ }^{17}$

\subsubsection{Data analysis}

Using descriptive statistics mean \pm and Standard Deviation (SD) were calculated for normally distributed continuous variables and frequency (percentage) was measured for categorical variables. Univariate analysis was conducted to identify the factors associated with child abuse and then, multivariate logistic regression analysis was used to evaluate the adjusted Odds Ratios (ORs). In this study, variables with a $p$-value of $<0.3$ in the univariate analysis were introduced into the multivariate logistic regression analysis. For presenting the adjusted ORs, a two-sided alpha level of 0.05 was considered as statistically significant. All the analyses were carried out using Stata software (version 14.1) (Stata Corp, College Station, TX, USA).

\subsection{Ethical considerations}

The present study was conducted in compliance with the Helsinki Declaration. The study was approved by the Ethics Committee of the Vice -Chancellery for Research and Technology, Kermanshah University of Medical Sciences (KUMS.REC.496) and a written informed consent was obtained from all the participants after explaining the purpose of research.

\section{Results}

In this study, a total of 273 drug-addicted parents were studied. Among which, 159 parents (58.2\%) had boy and 114 of them (41.8\%) had girl. Among the offspring, 118 of them (43.2\%) were abused. Fortyseven children (17.2\%) experienced physical abuse and 102 children (37.4\%) experienced psychological abuse. The highest level of education was high school diploma (53.5\%) or less (63.7\%) among the addicted fathers and mothers, respectively. The prevalence of psychiatric disorders in the family was equal to $39.2 \%(n=107)$. Among the families participated in the study, in $224(0.84 \%)$ families, fathers were addicted, in $27(0.09 \%)$ families, mothers were addicted, and in 22 $(0.08 \%)$ families, both parents were addicted. Table 1 shows other results.

As shown in Table 1, there was a significant relationship between gender of offspring (0.001), father's age (0.024), parent's educational level (0.001), mother's occupation (0.008), history of psychiatric disorders in family (0.001), number of siblings (0.035), parental addiction (0.007) and child abuse.

As shown in Chart 1, insult (61.6\%) and blaming (55.2\%) were among the most common types of psychological abuse in the boys and girls, respectively. Being fired from home (28.9\%) was the least common type of psychological abuse among both boys and girls.

As shown in Chart 2, slapping (52.2\%) and pinching (36.8\%) were among the most common types of physical abuse in the boys and girls, respectively. Burning (23.2\%) and throwing the equipment $(19.2 \%)$ were among the least prevalent types of physical abuse in the boys and girls, respectively.

After controlling other influential variables, child abuse in the boys was found to be 0.32 times more than the girls. However, with the increase in the age of parents, the chance of child abuse increased but after controlling gender and the number of siblings, no relationship was found between the age of parents and child abuse. After controlling the influential variables, it was found that the increase in the number of siblings increased the chances of child abuse such that, the children who had three or more than three siblings were 2.92 times more likely to be abused than those who did not have any siblings. It was also found that the positive history of psychiatric disorders in the family increased the chance of child abuse by 2.56 times. On the other hand, our findings showed that the chance of child abuse in the offspring whose parents were both addicted was 2.66 times more than those whose fathers were only addicted. This is while; the chance of child abuse in the families with the addicted father was $71 \%$ more than those with the addicted mother (Table 2).

\section{Discussion}

Our results showed that the prevalence of physical and psychological abuse was equal to $43.2 \%$ in the children with addicted parents. Malekshahi and Farhadi ${ }^{21}$ have investigated the prevalence of child abuse in the non-addicted families in Lorestan province, western Iran, and showed that the prevalence of physical and psychological child abuse was equal to 5.4 and $7.3 \%$, respectively. According to Kelley et al., ${ }^{4}$ and Dube et al., ${ }^{6}$ the prevalence of child abuse is significantly higher in the families with drug-addicted parents than non-addicted 
Table 1

Demographic and clinical characteristic of participant.

\begin{tabular}{|c|c|c|c|c|c|c|c|c|}
\hline \multirow[t]{3}{*}{ Variable } & \multirow{3}{*}{$\begin{array}{l}\text { Levels } \\
\text { Total prevalence }\end{array}$} & \multirow[t]{3}{*}{$\mathrm{N}(\%)$} & \multicolumn{2}{|c|}{ Physical \& Emotional abuse } & \multicolumn{2}{|c|}{ Physical abuse } & \multicolumn{2}{|c|}{ Emotional abuse } \\
\hline & & & $\mathrm{N}(\%)$ & $\mathrm{P}$ & $\mathrm{N}(\%)$ & $\mathrm{P}$ & $\mathrm{N}(\%)$ & $\mathrm{P}$ \\
\hline & & & $(43.2) 118$ & & $47(17.2)$ & & $102(37.4)$ & \\
\hline \multirow[t]{2}{*}{ Offspring gender } & Boy & $159(58.2)$ & $86(72.8)$ & $0.001>$ & $37(78.7)$ & 0.002 & $74(72.5)$ & $0.001>$ \\
\hline & Girl & $114(41.8)$ & $32(27.2)$ & & $10(21.3)$ & & $28(27.5)$ & \\
\hline \multirow[t]{3}{*}{ Offspring age } & $6-8$ & $105(38.5)$ & $47(39.8)$ & 0.143 & $22(64.8)$ & 0.101 & $41(40.1)$ & 0.013 \\
\hline & $9-10$ & $73(26.7)$ & $37(31.4)$ & & $15(31.9)$ & & $28(27.9)$ & \\
\hline & $11-12$ & $95(34.9)$ & $34(28.8)$ & & $10(21.2)$ & & $33(32.0)$ & \\
\hline \multirow[t]{3}{*}{ Father's age } & $25-35$ & $84(30.8)$ & $26(22.0)$ & 0.024 & $10(21.2)$ & 0.249 & $22(21.6)$ & 0.039 \\
\hline & $36-45$ & $140(51.3)$ & $68(57.6)$ & & $26(55.3)$ & & $59(57.9)$ & \\
\hline & $46-51$ & $49(17.9)$ & $24(20.4)$ & & $11(23.5)$ & & $21(20.5)$ & \\
\hline \multirow[t]{3}{*}{ Mother's age } & $25-35$ & $154(56.4)$ & $62(52.5)$ & 0.187 & $24(51.1)$ & 0.114 & $53(51.9)$ & 0.114 \\
\hline & $36-45$ & $90(33.0)$ & $39(33.0)$ & & $14(29.7)$ & & $35(34.4)$ & \\
\hline & $46-51$ & $29(10.6)$ & $17(14.5)$ & & $9(19.2)$ & & 14(13.7) & \\
\hline \multirow[t]{2}{*}{ Father's education } & Under the diploma and diploma & $146(53.5)$ & $77(65.3)$ & $0.001>$ & $25(53.1)$ & 0.965 & $68(66.6)$ & $0.001>$ \\
\hline & High school to diploma & $127(46.5)$ & $41(34.7)$ & & $22(46.9)$ & & $34(33.4)$ & \\
\hline \multirow[t]{2}{*}{ Mother's education } & Under the diploma and diploma & $174(63.7)$ & $88(74.5)$ & $0.001>$ & $33(70.2)$ & 0.310 & $77(75.5)$ & 0.002 \\
\hline & High school to diploma & $99(36.3)$ & $30(24.5)$ & & $14(29.8)$ & & $25(24.5)$ & \\
\hline \multirow[t]{2}{*}{ Father's occupation } & Self-employed & $198(72.5)$ & $90(76.2)$ & 0.227 & $33(70.2)$ & 0.696 & $76(74.5)$ & 0.571 \\
\hline & Employed & $75(27.5)$ & $28(23.8)$ & & 14(29.7) & & $26(25.5)$ & \\
\hline \multirow[t]{2}{*}{ Mother's occupation } & Housewife & $229(83.9)$ & $107(90.6)$ & 0.008 & $42(89.3)$ & 0.262 & $91(89.2)$ & 0.064 \\
\hline & Employed & $44(16.1)$ & $11(09.4)$ & & $5(10.7)$ & & $11(10.8)$ & \\
\hline \multirow[t]{2}{*}{ History of psychiatry disorders in the family } & Yes & $107(39.2)$ & $61(51.6)$ & $0.001>$ & $26(55.3)$ & 0.013 & $52(50.9)$ & 0.002 \\
\hline & No & $166(60.8)$ & $57(48.3)$ & & 21(44.7) & & $50(9.1)$ & \\
\hline \multirow[t]{3}{*}{ Number of siblings } & No & 32)11.7) & $8(6.8)$ & 0.035 & $1(2.1)$ & $(0.071)$ & $7(6.9)$ & $(0.62)$ \\
\hline & $1-2$ & 193(70.7) & $84(71.2)$ & & $38(80.9)$ & & $72(70.6)$ & \\
\hline & $\geq 3$ & $48(17.6)$ & $26(22.0)$ & & $8(17.0)$ & & $23(22.5)$ & \\
\hline \multirow[t]{3}{*}{ Parental addiction } & Father's & $224(82.1)$ & $97(82.2)$ & 0.007 & $40(85.1)$ & 0.572 & $86(84.3)$ & 0.034 \\
\hline & Mother's & $27(9.9)$ & $17(14.4)$ & & $5(10.6)$ & & 13(12.7) & \\
\hline & Both parents & $22(8.1)$ & $4(3.4)$ & & 2.43 & & $3(2.9)$ & \\
\hline
\end{tabular}

ones. High prevalence of child abuse in the addicted parents can be due to low control on impulsive behaviors, irritability and mood unsteadiness, especially during the discontinuation syndrome, ${ }^{8}$ more prevalence of mental disorders, ${ }^{18}$ and lack of necessary skills in coping with the crisis. $^{19}$

Investigation of different types of child abuse showed that psychological abuse was more prevalent than physical abuse, typically, psychological abuse is the most common form of child abuse, yet it is the most hidden type, which is reported less often. ${ }^{20}$ One of the reasons for high prevalence of psychological abuse is that psychological abuse is not visible like the physical abuse, and this abuse is practiced more by verbal means. In fact, instances of psychological abuse, such as verbal threats, aggression, neglect, and rejection by the parents and those responsible for childcare are not considered as abuse. In this regard, psychological abuse is the most covert and destructive type of abuse leading to personality disorders and lack of self-esteem and self confidence in the child. ${ }^{21,22}$ In terms of the age of parents, the results showed that physical and psychological abuse are more common among the fathers under 45 years of age. Younger parents are more exposed to tension because they have less financial resources and are more vulnerable to life-threatening outcomes. On the other hand, younger parents show less tolerance against inappropriate behaviors of the children and have less skill in coping with children's oppositional behaviors. ${ }^{23}$ Regarding the relationship between educational level of the parents and child abuse, parental education seems to be a protective factor through reforming the beliefs about physical intimacy, attitudes

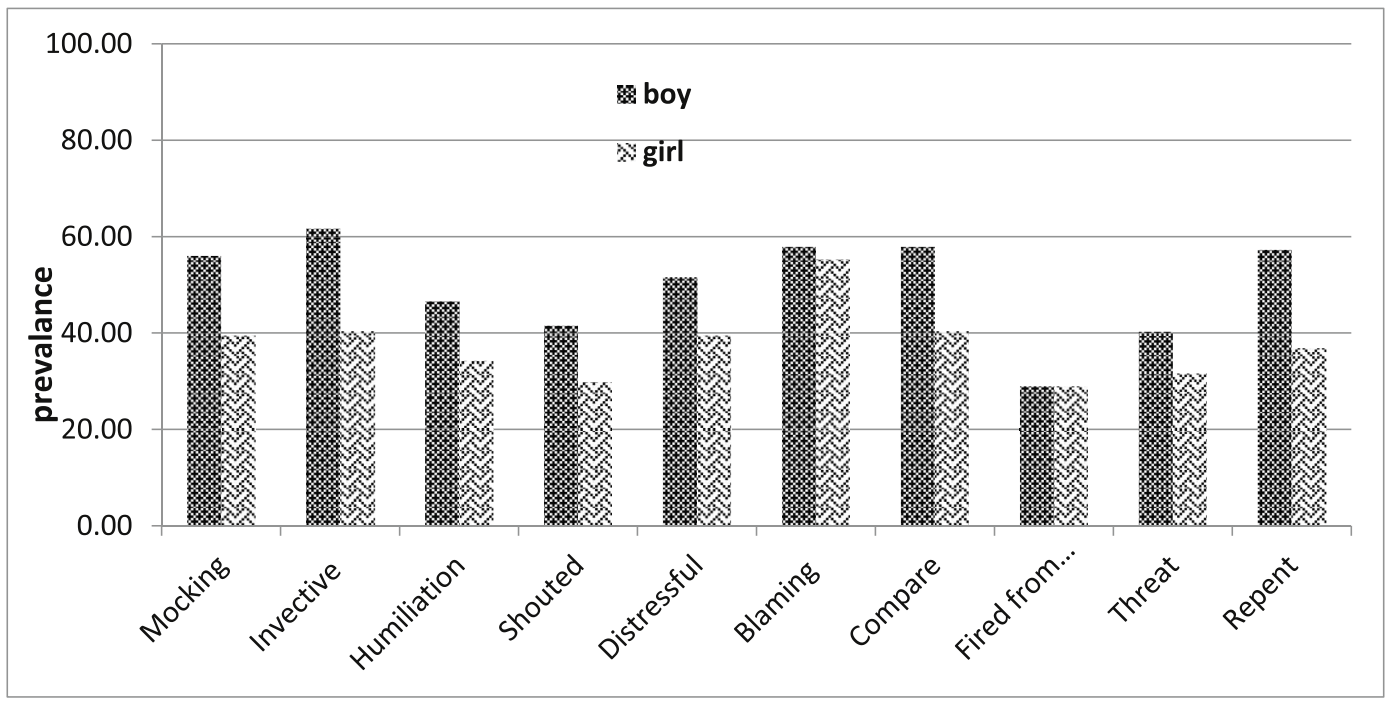

Chart 1. The prevalence of psychological abuse by sex. 


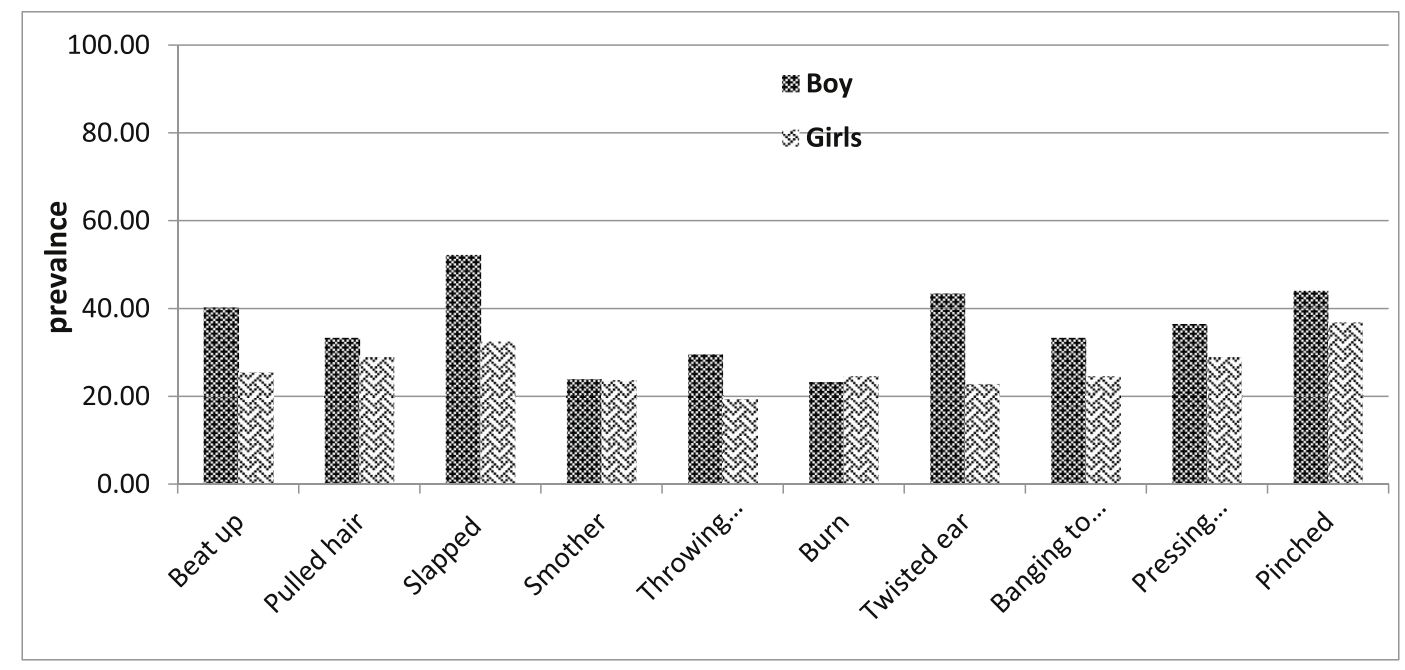

Chart 2. The prevalence of physical abuse by sex.

about children and parental improvements and increased resilience, and also development of social communication. ${ }^{24-26}$ Our results showed that, slapping and pinching were among the most common forms of physical abuse in the boys and girls, respectively. In the study by Andrew, it has been shown that slapping is the most common type of physical abuse, as most parents choose ways to punish their children, making them less likely to be injured. ${ }^{27}$ After controlling other influential factors, analysis of the results showed that child abuse in boys was 0.67 times more prevalent than the girls. This finding is in line with the results of other researches. ${ }^{28,29}$ Amini (2000), in a study showed that the prevalence of child abuse in the boys was 78.67 times more than the girls. Parents usually have different expectations regarding the behavior of girls and boys, and they may react differently to a specific behavior because of these different expectations, so boys are more likely to be physically punished. ${ }^{28}$ Also, the parents often use violent approaches to punish the boys, while they use less violent ones for punishing the girls. ${ }^{27}$

It was found that with the increase in the number of siblings, the chances of child abuse increase so that, children with three or more than three siblings was abused 2.92 times more than the children who

Table 2

Unavailable and multivariable of factors affecting of child abuse.

\begin{tabular}{|c|c|c|c|c|c|c|c|}
\hline \multirow[t]{2}{*}{ Variable } & & \multicolumn{2}{|c|}{ Physical \& psychological abuse } & \multicolumn{2}{|l|}{ Physical abuse } & \multicolumn{2}{|l|}{ Psychological abuse } \\
\hline & & Crude OR (95\% CI) & $\begin{array}{l}\text { Adjusted OR (95\% } \\
\text { CI) }\end{array}$ & Crude OR (95\% CI) & $\begin{array}{l}\text { Adjusted OR (95\% } \\
\text { CI) }\end{array}$ & Crude OR (95\% CI) & $\begin{array}{l}\text { Adjusted OR (95\% } \\
\text { CI) }\end{array}$ \\
\hline \multirow[t]{2}{*}{ Offspring gender } & Boy & 1 & 1 & 1 & 1 & 1 & 1 \\
\hline & Girl & $0.33(0.19-0.55)$ & $0.32(0.19-0.56)$ & $0.37(0.22-0.63)$ & $0.39(0.22-0.68)$ & $0.31(0.15-0.66)$ & $0.32(0.15-0.69)$ \\
\hline \multirow[t]{3}{*}{ Offspring age } & 6-8year & 1 & & 1 & & 1 & 1 \\
\hline & 9-10year & $1.26(0.69-2.30)$ & & $0.97(0.52-1.79)$ & & $0.97(0.46-2.03)$ & $0.90(0.41-1.95)$ \\
\hline & 11-12year & $0.68(0.38-1.21)$ & & $0.83(0.46-1.47)$ & & $0.44(0.19-0.99)$ & $0.40(0.17-0.93)$ \\
\hline \multirow[t]{3}{*}{ Father's age } & $25-35$ & 1 & & 1 & 1 & 1 & \\
\hline & $36-45$ & $2.10(1.19-3.72)$ & & $2.05(1.13-3.70)$ & $2.15(1.15-4.05)$ & $1.68(0.76-3.70)$ & \\
\hline & $46-51$ & $2.14(1.03-4.42)$ & & $2.11(1.00-4.45)$ & $1.92(0.85-4.33)$ & $2.14(0.83-5.49)$ & \\
\hline \multirow[t]{3}{*}{ Mother's age } & $25-35$ & 1 & & 1 & & 1 & \\
\hline & $36-45$ & $1.13(0.67-1.92)$ & & $1.21(0.70-2.07)$ & & $0.99(0.48-2.04)$ & \\
\hline & $46-51$ & $2.10(0.93-4.70)$ & & $1.77(0.79-3.96)$ & & $2.43(0.99-5.99)$ & \\
\hline \multirow[t]{2}{*}{ Father's education } & $\begin{array}{l}\text { Under the } \\
\text { diploma and } \\
\text { diploma }\end{array}$ & 1 & & 1 & 1 & 1 & \\
\hline & $\begin{array}{l}\text { High school to } \\
\text { diploma }\end{array}$ & $0.42(0.27-0.70)$ & & $0.42(0.27-0.70)$ & $0.44(0.26-0.77)$ & $1.01(0.54-1.90)$ & \\
\hline \multirow[t]{2}{*}{ Mother's education } & $\begin{array}{l}\text { Under the } \\
\text { diploma and } \\
\text { diploma }\end{array}$ & 1 & & 1 & & 1 & \\
\hline & $\begin{array}{l}\text { High school to } \\
\text { diploma }\end{array}$ & $0.42(0.25-0.71)$ & & $0.42(0.25-0.70)$ & & $0.70(0.35-1.38)$ & \\
\hline \multirow[t]{2}{*}{ Father's occupation } & Self-employed & 1 & & 1 & & 1 & \\
\hline & Employed & $0.71(0.41-1.23)$ & & $0.85(0.48-1.48)$ & & $1.14(0.57-2.28)$ & \\
\hline \multirow[t]{2}{*}{ Mother's occupation } & Housewife & 1 & 1 & 1 & & 1 & \\
\hline & Employed & $0.38(0.18-0.78)$ & $0.34(0.15-0.75)$ & $0.50(0.25-1.05)$ & & $0.57(0.21-1.53)$ & \\
\hline \multirow{2}{*}{$\begin{array}{l}\text { History of psychiatry } \\
\text { disorders in the } \\
\text { family }\end{array}$} & No & 1 & 1 & 1 & 1 & 1 & 1 \\
\hline & Yes & $2.53(1.53-4.17)$ & $2.56(1.50-4.38)$ & $2.19(1.32-3.69)$ & $1.82(1.05-3.53)$ & $2.21(1.17-4.18)$ & $2.19(1.11-4.31)$ \\
\hline \multirow[t]{3}{*}{ Number of siblings } & No & 1 & 1 & 1 & & 1 & \\
\hline & $1-2$ & $2.31(0.98-5.40)$ & $2.42(1.00-5.90)$ & $2.12(0.87-5.16)$ & & $7.56(1.00-11.44)$ & \\
\hline & $\geq 3$ & $3.54(1.32-9.45)$ & $2.92(1.02-8.29)$ & $3.28(1.19-9.03)$ & & $4.19(1.73-9.22)$ & \\
\hline \multirow[t]{3}{*}{ Parental addiction } & Father's & 1 & 1 & 1 & 1 & 1 & \\
\hline & Mother's & $0.29(0.09-0.88)$ & $0.25(0.07-0.83)$ & $0.25(0.07-0.88)$ & $0.23(0.06-0.84)$ & $0.46(0.10-2.04)$ & \\
\hline & Both parents & $2.22(0.97-5.07)$ & $2.66(1.07-6.58)$ & $1.49(0.66-0.33)$ & $1.59(0.67-3.7)$ & $1.04(0.37-2.92)$ & \\
\hline
\end{tabular}


had no siblings. Alreshoud (1997) in a research showed that the risk of child abuse is higher in more populous families. Gelles (1997) showed that the prevalence of child abuse is higher in the families with two children than single-child families. According to the resource dilution model, the greater the number of children, the calmness and material resources of the parents are more limited, and the risk of child abuse increases. According to this theory, family resources are diminished as the size of the household grows, which in turn causes negative and undesirable consequences for the child. ${ }^{30-32}$ Being a housemaker mother also increased the chance of child abuse by 0.62 . Although, home duties may be shared between the couples in Iran, however, housemaker mothers are the primary caregivers and receive less direct support. ${ }^{33}$ Undoubtedly, addiction makes the mothers continually think about their physical and mental needs and dependencies and as a result, they cannot do their native tasks well. ${ }^{3}$ The existence of psychological problems in the family increased the chance of child abuse by 2.56 times. This finding is consistent with findings of other researches. ${ }^{34}$ For more explaining on this finding, it can be argued that the presence of addiction and mental disease may make the parents to be less capable of providing suitable shelter for their children that results in development of child abuse due to the presence of more social problems, less economic stability, defective diagnostic power, and emotional irregularity in the parents. ${ }^{35}$ Also, comorbidity of addiction and psychological problems have an adverse effect on the parenting styles making the parents to have communication problems with their children and often providing hostile, aggressive, and rejecting environments at home. ${ }^{6}$

The chance of child abuse in the families where both parents were addicted was 2.66 times more than those where only the father was addicted. For explaining on this finding, it can be stated that, low social support, high stress, social isolation, marital dissatisfaction, negative life experiences, poor interactions with the relatives, and economic problems are more common in the families where both parents are addicted and all of these factors may cause the child abuse. ${ }^{6,8}$

Although, in the present study, the family risk factors of physical and psychological child abuse were discussed in the addicted families, but further studies are needed to determine and investigate other influential factors.

Small sample size and merely using the self-report questionnaire were among the limitations of the present study. Accordingly it is recommended to investigate other types of child abuse, such as neglect and sexual abuse in the future studies with a larger sample size and conduct interviews with the children if possible.

\section{Conclusion}

Given high prevalence of child abuse in the families with addicted parents, supporting organizations should play a greater role in this regard. Since, the child abuse has negative effects on the future of children; care programs are required to empower these children. The results of the present study highlighted the need for screening of child abuse in the families with addicted parents, teaching the parents to prevent the child abuse and its related consequences, and training the psychologists and social workers in the addiction treatment centers about referral of child abuse cases to medical and legal centers.

\section{Financial support and sponsorship}

The financial support of this article was conducted by Substance Abuse Prevention Research Center, Vice Chancellor for research and Research and Technology, Kermanshah University of Medical Sciences, Kermanshah, Iran (Grant number:96510).

\section{Funding}

This article is the result of the findings of the research project that was approved and financed by the Substance Abuse Prevention
Research Center, Vice Chancellor for research and Research and Technology, Kermanshah University of Medical Sciences, Kermanshah, Iran ( Grant no: 96510).

\section{Declaration of competing interest}

The authors declared no conflicts of interest. No funding was received for this study.

\section{Acknowledgements}

The authors would like to thank the Substance abuse prevention research center and clinical Research Development Unit (CRDU) of Emam Khomeini, Mohammad Kermanshahi and Farabi Hospital, university of Medical sciences, Kermanshah, Iran for their cooperation and scientific assistance throughout the period of study.

\section{References}

1. Farnia V, Tatari F, Salemi S, et al. Effect of Trauma-Focused Cognitive Behavioral Therapy on Reduction Social and Emotional Maladjustment of Physically Abused Children: A Clinical Trial2017. 5473-5481 p.

2. Krug E, Mercy J, Dahlberg L, Zwi A. The World Report on Violence and Health. 2002; 2002:1083-1088.

3. Almuneef MA, Alghamdi LA, Saleheen HN. Family profile of victims of child abuse and neglect in the Kingdom of Saudi Arabia. Saudi Med J. 2016;37(8):882-888.

4. Kelley M, Lawrence H, Milletich R J, Hollis B, Henson J M. Modeling Risk for Child Abuse and Harsh Parenting in Families with Depressed and Substance-Abusing Parents. 2015; 2015.

5. Khoshabi K, Habibi M, Farzadfard Z, Mohammadkhani P. The prevalence of child abuse in Tehran secondary school students. J Soc Welfare. 2006;7(27):115-127.

6. Dube SR, Anda RF, Felitti VJ, Croft JB, Edwards VJ, Giles WH. Growing up with parental alcohol abuse: exposure to childhood abuse, neglect, and household dysfunction. Child Abuse Neglect. 2001;25(12):1627-1640.

7. Gruber K, Floyd Taylor Ph D, Lcsw M. A Family Perspective for Substance Abuse: Implications from the Literature. 2006; 2006:1-29.

8. Hien D, Cohen LR, Caldeira NA, Flom P, Wasserman G. Depression and anger as risk factors underlying the relationship between maternal substance involvement and child abuse potential. Child Abuse Neglect. 2010;34(2):105-113.

9. Bennett DS, Bendersky M, Lewis M. Children's cognitive ability from 4 to 9 years old as a function of prenatal cocaine exposure, environmental risk, and maternal verbal intelligence. Dev Psychol. 2008;44(4):919-928.

10. Solis JM, Shadur JM, Burns AR, Hussong AM. Understanding the diverse needs of children whose parents abuse substances. Curr Drug Abuse Rev. 2012;5(2):135-147.

11. Farnia V, Naami A, Zargar Y, et al. Comparison of trauma-focused cognitive behavioral therapy and theory of mind: improvement of posttraumatic growth and emotion regulation strategies. J Educ Health Promot. 2018;7:58.

12. Leonard KE, Das Eiden R. Cognitive functioning among infants of alcoholic fathers. Drug Alcohol Depend. 2002;67(2):139-147.

13. Hussong AM, Zucker RA, Wong MM, Fitzgerald HE, Puttler LI. Social competence in children of alcoholic parents over time. Dev Psychol. 2005;41(5):747-759.

14. Rehan W, Antfolk J, Johansson A, Jern P, Santtila P. Experiences of severe childhood maltreatment, depression, anxiety and alcohol abuse among adults in Finland. PloS One. 2017; 12(5):e0177252

15. van der Kooij IW, Nieuwendam J, Bipat S, Boer F, Lindauer RJ, Graafsma TL. A national study on the prevalence of child abuse and neglect in Suriname. Child Abuse Neglect. 2015;47:153-161.

16. Farina V, Salemi S, Tatari F, et al. Trauma-focused cognitive behavioral therapy a clinical trial to increase self-efficacy in abused the primary school children. $J$ Educ Health Promot. 2018;7:33.

17. Hosseinkhani Z, Nedjat S, Majdzadeh R, Mahram M, Aflatooni A. Design of the child abuse questionnaire in Iran. J School Publ Health 2014:11(3):29-38.

18. Berg MK, Hobkirk AL, Joska JA, Meade CS. The role of substance use coping in the relation between childhood sexual abuse and depression among methamphetamine users in South Africa. Psychol Trauma Theor Res Pract Pol. 2017;9(4):493-499.

19. Malekshahi F, Farhadi A. Prevalence of child abuse in Khorramabad junior high school students. yafte. 2012;15(5):31-39.

20. Barnett O, Miller-Perrin C, Perrin R. Family Violence across the Lifespan: An Introduction. California: Sage; 2005

21. Wong W, Leung P, Tang SK, Chen W-Q, Lee A, C Ling D. To Unfold a Hidden Epidemic: Prevalence of Child Maltreatment and its Health Implications Among High School Students in Guangzhou, China. 2009; 2009:441-450.

22. Khalid M. Perceptions of Emotional Abuse with Respect to Depression, Anxiety and Low Self-Esteem Among Pakistani Women from Low Income Families2015.

23. Sidebotham P, Golding J. Child maltreatment in the "children of the nineties" a longitudinal study of parental risk factors. Child Abuse Neglect. 2001;25(9):1177-1200.

24. Li F, Godinet M, Arnsberger P. Protective factors among families with children at risk of maltreatment: follow up to early school years. Child Youth Serv Rev. 2011;33:139-148. 
25. Wu SS, Ma CX, Carter RL, et al. Risk factors for infant maltreatment: a populationbased study. Child Abuse Neglect. 2004;28(12):1253-1264.

26. Scannapieco M, Connell-Carrick K. Focus on the First Years: Correlates of Substantiation of Child Maltreatment for Families with Children 0 to 4. 2005; 2005:1307-1323.

27. Amini M. Iran Medical Universit Investigation of Epidimiology Child Abuse in Rafsanjan. Iran university of medical Scinces; 2000.

28. Mahoney A, Donnelly WO, Lewis T, Maynard C. Mother and father self-reports of corporal punishment and severe physical aggression toward clinic-referred youth. $J$ Clin Child Psychol. 2000;29(2):266-281.

29. Scher CD, Forde DR, McQuaid JR, Stein MB. Prevalence and demographic correlates of childhood maltreatment in an adult community sample. Child Abuse Neglect. 2004;28(2):167-180.

30. Alreshoud A. Child Abuse and Neglect Among Delinquents in Saudi Arabia. Pittsburgh: University of Pittsburgh; 1997.
31. Gelles R. Intimate Violence in Families. third ed. Thousand Oaks, CA, US: Sage Publications, Inc.; 1997.

32. McHale SM, Updegraff KA, Whiteman SD. Sibling relationships and influences in childhood and adolescence. J Marriage Fam. 2012;74(5):913-930.

33. Khosravan SP, Sajjadi MP, Moshari JMD, Barzegar Shoorab Sofla FM. The effect of education on the attitude and child abuse behaviors of mothers with 3-6 Year old children: a randomized controlled trial study. Int J Community Based Nurs Midwifery. 2018;6(3):227-238.

34. Walsh C, MacMillan H, Jamieson E. The relationship between parental psychiatric disorder and child physical and sexual abuse: findings from the Ontario Health Supplement. Child Abuse Neglect. 2002;26(1):11-22.

35. Kohl PL, Jonson-Reid M, Drake B. Maternal mental illness and the safety and stability of maltreated children. Child Abuse Neglect. 2011;35(5):309-318. 